\title{
El devenir ("llegar a ser") de la Ginecobstetricia en Antioquia
}

\author{
Gustavo Casas Vásquez*
}

Con el advẹnimiento del vigésimo congreso colombiano de Obstetricia y Ginecología, hemos sido invitados a elaborar un recuento de las actividades de nuestra especialidad en Antioquia y así enviarles a nuestros colegas del país y el exterior una invitación a asistir y a compartir con esfuerzo mutuo la calidad excepcional del evento.

Como especialidad, la historia de la Ginecología y la Obstetricia en nuestro medio se inicia apenas a mediados del siglo pasado. Su ejercicio fue precedido por la práctica de la cirugía general y la medicina. Debió superar hartos escollos, como la carencia de substrato científico, la politiquería y la pobreza, antes de lograr colocarse en el interior del partenón médico.

Sin ambages, se puede dividir esta crónica en dos etapas: antes y después del Dr. Jaime Botero Uribe.

\section{Antes}

El fundador de los estudios médicos en Antioquia fue el doctor José María Martínez Pardo, quien la enseñaba en Santafé de Antioquia en 1837. Luego vino la expedición de diplomas médicos por la Universidad de Antioquia desde 1857. Pero la práctica de la obstetricia la inició un distinguido bogotano amigo de Santander (y por ello refugiado en estas breñas), el Dr. José Ignacio Quevedo Amaya quien a principios de 1844 practicó con éxito la primera laparotomía y cesárea de América a doña Ana Joaquina Echeverría de P. vecina de - un suburbio de Medellín-, con lo cual se abrió paso entre los doctos examinadores médicos, que calificaban los candidatos a ejercer la profesión.

Se tienen noticias de que no existía la consulta prenatal ni la evaluación por el médico de las parturientas en el siglo 19. Las comadronas eran las encargadas de atenderlas a domicilio y, el partero (que era un médico graduado) era llamado generalmente para ayudar al bien morir de las criaturas o madres, o de ambas. Estas repetidas frustraciones y penas, fueron creando el campo abonado para bienvenir a aquellos parteros que comenzaron a prepararse para ofrecerles mejores opciones.

Entre los 32 médicos graduados por la Universidad de Antioquia en el siglo pasado, el Dr. Nepomuceno Jiménez fue el primero que viajo en chalupas, champanes y botes de vela a estudiar en París, Obstetricia y Ginecología. A su regreso se encontró con la secularización del ciclo

* Asociación Antioqueña de Obstetricia y Ginecología.
"Comadrona -partero-Basioptrivo" más cesáreas sólo para pre y post mortem.

Sinembargo se fue creando un grupo de discípulos que poco a poco fueron mejorando los pronósticos de los casos atendidos por ellos en última instancia. Le correspondió al Dr. Alberto Bernal Nicholls lograr establecer las primeras consultas prenatales y con ello lograr la mayor afluencia de parturientas a los hospitales. Pero fue en el servicio de cirugía donde el Dr. Gil J. Gil practicó la primera cesárea segmentaria en 1923 en un caso de parto difícil por estrechez. Las dificultades impuestas por la carencia de medios provisores de logística, desencadenaron una época de antagonismos entre quienes preconizaban la cesárea y el basioptrivo. Pero la universidad preparaba a Benicio Gaviria, Jorge Henao Posada y Rafael Vélez Gil —entre otros-para que le imprimiera el sello del prestigio a la práctica tocológica, de los años 40 en adelante.

En Antioquia, la Ginecología hizo un camino aparte. Nació su práctica de la concepción meramente quirúrgica en manos de brillantes cirujanos. En los 10 primeros años del siglo 20, el "mejor cirujano de Colombia", el Dr. Juan B. Montoya y Flórez había practicado con éxito 59 histerectomías vaginales de tal forma que la Facultad de Medicina le autorizó para crear la cátedra de ginecología en 1920, adjunta a la cátedra de cirugía general. De tal prestigio gozaba el Dr. Montoya que en 1916 fue invitado por los hermanos Mayo a efectuar demostraciones quirúrgicas en su clínica de Rochester, Minnesota. Entretanto, había nacido el 24 de septiembre de 1890 en Envigado, Pedro Nel Gil Cardona Correa, quien viajó a París a estudiar Anatomía Patológica, fundando a su regreso dicha cátedra. La razón principal de esa inquietud residía en traer la biopsia a Medellín como elemento previo indispensable para el tratamiento (con Radium) del cáncer ginecológico. En 1928, el Dr. Gil J. Gil (llamado el bisturí de oro y, quien llegó a practicar más de diez mil operaciones), permitió independizar la cátedra de ginecología, bajo la dirección del Dr. Cardona, quien a partir de ese momento, desarrollo con su talento la inquietud y el amor que le tenía a la especialidad al intuir que el verdadero substrato de la ginecología estaba en la Endocrinología y, con la depurada técnica quirúrgica aprendida de sus tutores, inició en Colombia el respeto y acatamiento médicos por la especialidad. Tenía el don de la comunicación a través del ejemplo y la enseñanza y formó entonces discípulos tan brillantes como René Díaz Correa, Luis Tirado Vélez, su hijo Fernando, y muchos más que hoy forman parte de la constelación que ilumina el firmamento colombiano. 


\section{Después}

Por allá por los años 50 era decano de la Facultad de Medicina un verdadero y revolucionario líder: Ignacio Vélez Escobar, él había percibido de cerca la brillante escuela norteamericana que se iniciaba, e hizo todos los contactos conducentes al envío de numerosos médicos al exterior con el propósito de capacitarles para mejorar nuestra medicina en Antioquia. Fue así como partió a Rochester el Dr. Jaime Botero Uribe quien a su regreso en 1956, fue nombrado Jefe del Servicio de Ginecología y Obstetricia, colocando pues la piedra de Ara sobre el altar donde a partir de entonces fueron uncidos los especialistas que desparramados por el país y el exterior, forman la pléyade que hoy es mirada con respeto y devoción.

La enseñanza de la Ginecología y la Obstetricia se hacía mediante clases magistrales, que fueron reempla- zadas por sesiones participativas, clubes de revistas, presentación de seminarios etc. y estableció el Dr. Botero la docencia participativa en el cuidado activo de las pacientes. Integró las dos ramas, como implicación de los procesos reproductivos que tenían lugar en el organismo femenino. Paulatinamente creó líderes que hoy son prez de la docencia en Colombia y émulos de su sabiduría.

Sin lugar a dudas las escisiones creadas en la Universidad de Antioquia y que, ahora integran núcleos distinguidísimos de formación profesional en Ginecología y Obstetricia (como el C.E.S. y la Bolivariana), han sido conformadas por gentes preparadas en el servicio de Ginecología que revolucionó el Dr. Botero quien ahora preside el XX Congreso Colombiano de Obstetricia y Ginecología y la Asociación Antioqueña de Obstetricia y Ginecología.

\section{PUBLICACIONES}

Informamos a nuestros lectores que en la oficina de la Revista Colombiana de Obstetricia y Ginecología se encuentra a disposición para consulta las siguientes revistas:

- Internacional Journal of Gynecology \& Obstetrics

- Journal Brasilero de Ginecología

- Anales Chirurgiae et Gynaecologiae

- World Health Organization - Challenges in Reproductive Helth research

- Women's groups. NGOS and Safe Motherhood

- Revista Ecuatoriana de Ginecología y Obstetricia

- International Family Planning Perspectives

- Toko Ginecología Práctica

- Manual de Administración en Planificación Familiar

- Revista Obstetricia y Ginecología de Venezuela

- Revista Centroamericana de Obstetricia y Ginecología 